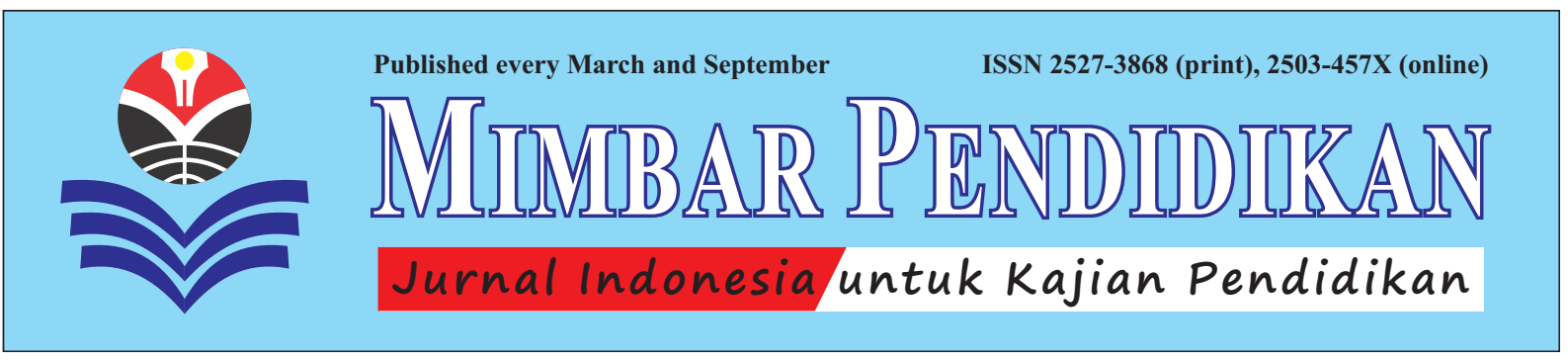

\title{
NURDIN
}

\section{Pengaruh Motivasi Mengajar dan Persepsi atas Lingkungan Sekolah terhadap Kinerja Guru}

\begin{abstract}
ABSTRAKSI: Dalam rangka meningkatkan mutu pendidikan, guru mempunyai peranan yang sangat penting dalam melaksanakan pengajaran dan pembelajaran. Kemampuan guru untuk dapat menciptakan suasana kondusif di dalam kelas sangat ditentukan oleh kondisi lingkungan setempat. Penelitian ini bertujuan untuk mengetahui pengaruh motivasi mengajar dan persepsi atas lingkungan sekolah terhadap kinerja guru. Metode penelitian merupakan penelitian survey. Subjek penelitian ini adalah 120 siswa, yang diambil secara acak di SMA (Sekolah Menengah Atas) Negeri 1 Tambun, Bekasi, Jawa Barat, Indonesia, pada tahun ajaran 2015/2016. Data dikumpulkan dengan instrumen angket dengan menggunakan skala Likert. Keabsahan data diperoleh dengan uji validitas dan reliabilitas, dan semua data memiliki distribusi normal. Hasil penelitian menunjukan bahwa motivasi mengajar memberi pengaruh yang signifikan terhadap kinerja guru. Begitu juga persepsi atas lingkungan sekolah memberi pengaruh yang signifikan terhadap kinerja guru. Koefisien determinasi $\left(R^{2}\right)$ menunjukan bahwa motivasi mengajar dan persepsi atas lingkungan sekolah mempunyai hubungan kuat terhadap kinerja guru.

KATA KUNCI: Motivasi Mengajar; Persepsi; Lingkungan Sekolah; Kinerja Guru; Mutu Pendidikan.
\end{abstract}

ABSTRACT: "The Influence of Teaching Motivation and Perception of the Environment on the Performance of School Teachers". In order to increase the quality of education, teachers have a very important role in implementing the teaching and learning. The ability of teachers to create conducive atmosphere in the classroom is determined by the local environmental conditions. This study is aimed to determine the effect of teaching motivation and perception of the school environment on teacher performance. It adopted a survey research method. The subjects were 120 students drawn randomly from SMAN (Public Senior High School) 1 Tambun, Bekasi, West Java, Indonesia, in the academic year of 2015/2016. Data were collected by questionnaires using Likert scale. The data were tested for the validity and reliability; all data were normally distributed. The results show that the motivation of teaching had a significant influence on the performance of the teachers. The perception of the school environment also had a significant influence on the performance of the teachers. The coefficient of determination (R2) indicates that the motivation of teaching and the perception of the school environment had a strong correlation to the performance of the teachers.

KEY WORD: Motivation of Teaching; Perception; School Environment; Teacher Performance; Quality of Education.

About the Author: Dr. Nurdin adalah Dosen Senior di STIE (Sekolah Tinggi Ilmu Ekonomi) Sailendra, Jalan Margasatwa No.99-B Pondok Labu, Jakarta Selatan, Indonesia. Untuk kepentingan akademis, penulis bisa dihubungi dengan nomor HP (Hand Phone): +6281399968520 atau alamat emel: nur.albaniah@ymail.com

How to cite this article? Nurdin. (2017). "Pengaruh Motivasi Mengajar dan Persepsi atas Lingkungan Sekolah terhadap Kinerja Guru" in MIMBAR PENDIDIKAN: Jurnal Indonesia untuk Kajian Pendidikan, Vol.2(1) March, pp.33-42. Bandung, Indonesia: UPI [Indonesia University of Education] Press, ISSN 2527-3868 (print) and 2503-457X (online).

Chronicle of the article: Accepted (October 25, 2016); Revised (January 25, 2017); and Published (March 30, 2017). 


\section{PENDAHULUAN}

Dalam rangka meningkatkan mutu pendidikan, guru mempunyai peranan yang sangat penting dalam melaksanakan pembelajaran untuk membantu peserta didik supaya mudah memahami materi pelajaran (Dimyati \& Moedjianto, 1992; dan Sallis \& Jones, 2002). Kemampuan guru untuk dapat menciptakan suasana kondusif didalam kelas, pada saat berlangsungnya proses belajarmengajar itu, sangat ditentukan oleh kondisi lingkungan setempat. Sekolah merupakan salah satu tempat untuk menyelenggarakan pendidikan yang perlu ditata dengan baik, supaya dapat membangkitkan motivasi guru, baik dalam mengajar maupun memotivasi peserta didik dalam mengikuti pelajaran, sehingga proses belajar-mengajar dapat berlangsung dengan baik.

Kemampuan guru dalam menyampaikan materi, supaya mudah dipahami oleh siswa, merupakan salah satu faktor penting untuk meningkatkan kualitas pendidikan (Segall, 1999; dan Tilaar, 2001). Kinerja guru mempunyai peranan yang sangat penting dalam keberhasilan peserta didiknya. Semua guru diharapkan memiliki tujuan untuk mencerdaskan anak didiknya supaya dapat mandiri, kreatif, dan berprestasi (Reigeluth \& Merril, 1963; dan Sudjana, 2001). Untuk itu, guru perlu memiliki motivasi mengajar, karena dipandang dapat memainkan peran penting, terutama dalam membantu peserta didik untuk membangun sikap positif dalam belajar, membangkitkan rasa ingin tahu, mendorong kemandirian, dan menciptakan kondisi untuk sukses dalam belajar. Peran ini merupakan tanggung jawab guru untuk menjadikan peserta didik dari tidak tahu menjadi tahu (Piaget, 1985; Klausmeir, 1991; dan Melinda \& Russel, 1997).

Salah satu solusi untuk mengatasi permasalahan tersebut, lingkungan sekolah seperti sarana dan prasarana perlu diperbaiki; dan guru dituntut untuk membangun dirinya, terutama meningkatkan motivasi dalam melaksanakan pembelajaran, sehingga peserta didik dapat mengikuti pelajaran dengan baik supaya pengetahuan siswa meningkat.

Kinerja Guru. Menurut R.L. Atkinson \& E.R. Hilgard (1982), kinerja adalah perilaku mengenai pengetahuan atau informasi yang diterima dan dapat diamati (Atkinson \& Hilgard, 1982). Manakala J. Whitmore (1997) menyatakan bahwa kinerja sebagai perilaku menunjuk pada suatu aktivitas yang, baik secara langsung maupun tidak langsung, diamati oleh orang lain (Whitmore, 1997). Sadar Malayu S.P. Hasibuan (2001) juga menyatakan bahwa kinerja adalah suatu hasil kerja yang dicapai seseorang dalam melakukan tugas-tugas yang dibebankan kepadanya, yang didasarkan atas kecakapan, pengalaman, dan kesungguhan (Hasibuan, 2001).

Kinerja, dengan demikian, dapat dicapai apabila guru termotivasi untuk melaksanakan pembelajaran dengan baik. Dalam konteks ini, G. Desler (2000) berpendapat bahwa kinerja adalah suatu proses kerja secara aktual, sesuai sasaran organisasi (Desler, 2000). Menurut O. Sutisna (2000), kinerja atau performance adalah perilaku yang menunjukan kompetensi yang relevan dengan tugas yang realistis untuk memenuhi kebutuhan organisasi (Sutisna, 2000).

Sementara itu, menurut Hasan Alwi et al. eds. (1995), kinerja meliputi tiga hal penting, yaitu: sesuatu yang dicapai; prestasi yang diperlihatkan; dan sesuatu kemampuan kerja (Alwi et al. eds., 1995). L.J. Moleong (1998) juga menyatakan bahwa kinerja adalah hasil yang diinginkan dari suatu organisasi (Moleong, 1998). Syaiful Bahri Djamarah (2006) akhirnya menyatakan bahwa pengetahuan dan kemampuan tentang tugas akan menentukan kinerja seseorang (Djamarah, 2006).

Mengenai guru, pendapat Rusman (2009), yang juga dikutip oleh A.D.S. Krissandi \& Rusmawan (2015), mengemukakan bahwa sumber daya pendidikan, seperti sarana, prasarana, biaya, organisasi, dan lingkungan, merupakan kunci keberhasilan pendidikan, 
tetapi kunci utamanya adalah guru (Rusman, 2009; dan Krissandi \& Rusmawan, 2015:463).

Guru, dengan demikian, merupakan faktor penting dalam melaksanakan pembelajaran; dan kunci keberhasilan suatu pendidikan tergantung pada kualitas guru (Russel \& Heinrich, 1989; dan Nurdin, 2014). Berdasarkan UU Sisdiknas (Undang-Undng Sistem Pendidikan Nasional) Nomor 2 Tahun 2003, pasal 39 ayat 2, disebutkan bahwa pendidik atau guru merupakan tenaga profesional yang bertugas merencanakan dan melaksanakan proses pembelajaran, menilai hasil pembelajaran, melakukan pembimbingan dan pelatihan, serta melakukan penelitian dan pengabdian kepada masyarakat (Depdiknas RI, 2003).

Selanjutnya, pada pasal 40 ayat 2 dinyatakan juga mengenai kewajibankewajiban guru, yaitu: (1) menciptakan suasana pendidikan yang bermakna, menyenangkan, kreatif, dinamis, dan dialogis; (2) mempunyai kemampuan secara profesional untuk meningkatkan mutu pendidikan; serta (3) memberi teladan dan menjaga nama baik lembaga, profesi, dan kedudukan sesuai dengan kepercayaan yang diberikan kepadanya (Depdiknas RI, 2003).

Dalam pada itu, O. Sutisna (2000) menyatakan bahwa guru adalah pendidik atau orang dewasa yang bertanggung jawab memberi bimbingan atau bantuan kepada anak didik dalam perkembangan jasmani dan rohaninya agar mencapai kedewasaan, mampu berdiri sendiri, dapat melaksanakan tugasnya sebagai makhluk Allah di muka bumi, serta sebagai makhluk sosial yang sanggup berdiri sendiri (Sutisna, 2000). Menurut Umaedi (1998), guru adalah pendidik, yang berarti orang dewasa yang melaksanakan tugas dan bertujuan untuk mendewasakan anak (Umaedi, 1998).

Sementara itu, "dewasa", menurut Moh Nazir (1997), adalah dewasa secara rohani dan jasmani dalam perkembangan dan perutumbuhan. Selanjutnya dikatakan bahwa dewasa secara rohani dan jasmani, yaitu: (1) dewasa sosial, dimana seseorang sanggup memahami tugas-tugas kemasyarakatan yang dibebankan kepadanya; (2) dewasa moril, dimana seseorang telah sanggup mengadakan pilihan mengenai apa yang disebut baik dan buruk, dan mampu mengadakan pertimbangan dan pilihan tentang yang mana lebih baik; serta (3) dewasa religius, dimana orang memiliki kemampuan untuk memilih dan mempertimbangkan dengan tepat ajaran agama yang mana ia harus yakini (Nazir, 1997).

Motivasi Mengajar. Suradinata (1996) mengemukakan bahwa motivasi adalah tenaga pendorong atau penggerak yang menyebabkan adanya tingkah-laku ke arah tujuan tertentu (Suradinata, 1996). J.L. McGaugh (1977) juga menyatakan bahwa motivasi merupakan dasar kekuatan atau daya yang menggerakan orang untuk berprilaku (McGaugh, 1977). Sementara itu, Slameto (1991) menyatakan bahwa motivasi merupakan suatu dorongan yang menyebabkan seseorang melakukan sesuatu perubahan energi untuk menciptakan kondisi atau sistem lingkungan, yang mendukung dan memungkinkan untuk berlangsungnya proses belajar (Slameto (1991).

Selanjutnya dikemukakan bahwa motivasi adalah faktor yang ada dalam diri manusia, yang dapat mendorong atau menimbulkan perilaku tertentu. Menurut Suradinata (1996) dan Abraham H. Maslow (2006), dikemukakan bahwa apabila kebutuhan yang rendah telah dipenuhi, maka manusia berupaya untuk memenuhi kebutuhankebutuhan yang lebih tinggi (Suradinata, 1996; dan Maslow, 2006).

Motivasi sendiri berasal dari kata motif, yang artinya sesuatu yang mendorong dari dalam diri seseorang untuk melakukan suatu gerakan (Gagne, 1977; Bloom, 1981; dan Krathwol \& Anderson, 2001). Sedangkan motivasi adalah sesuatu yang membuat orang untuk bertindak atau berperilaku dalam cara-cara tertentu yang didasarkan dari motif (Suradinata, 1996). Memotivasi manusia, dengan demikian, adalah menunjukan arah 
dan tujuan tertentu, yang dilakukan untuk berperan aktif dalam mengambil langkahlangkah yang dibutuhkan untuk memastikan bahwa manusia tersebut menuju dan bergerak ke arah yang telah ditentukan.

Sedangkan pengertian motivasi, menurut Hadi Joewono (1985) dan R.S. Schuler \& V.L. Huber (1993), adalah kondisi mental yang mendorong aktivitas dan memberi energi yang mengarah kepada pencapaian kebutuhan, memberi kepuasan atau mengurangi ketidakseimbangan (Joewono, 1985; dan Schuler \& Huber, 1993). Dari pendapat tersebut dapat disimpulkan bahwa motivasi menekankan pada kondisi mental manusia, sehingga bisa mendorong pada aktivitas dan juga memberikan kekuatan untuk bergerak ke arah sebagaimana yang diharapkan.

Menurut Suradinata (1996) lagi, bahwa terdapat lima faktor yang mempengaruhi motivasi manusia, yaitu: kebutuhan manusia, dorongan dan disiplin, penghargaan, lingkungan kerja, serta pencapaian tujuan. Dari kelima faktor tersebut, ianya sangat berpengaruh terhadap manusia agar dapat berbuat sehingga tujuan dapat tercapai (Suradinata, 1996).

Mengenai mengajar, M.N. Nasution (2001) mengatakan bahwa mengajar adalah segenap aktivitas kompleks yang dilakukan guru dalam mengorganisasi atau mengatur lingkungan sebaik-baiknya, sehingga terjadi proses belajar (Nasution, 2001). Dengan demikian, keberhasilan belajar siswa turut ditentukan oleh peran guru selama interaksi proses belajar-mengajar itu berlangsung. Dalam proses belajar-mengajar di kelas, guru membantu siswa dan memberikan bimbingan secara individu bagi siswa yang mengalami kesulitan mengerjakan tugas dan hasil belajar (Sumarno et al., 1994).

Oemar Hamalik (2000) mengemukakan bahwa mengajar dapat diartikan sebagai: (1) menyampaikan pengetahuan kepada siswa; (2) mewariskan kebudayaan kepada generasi muda; (3) usaha mengorganisasi lingkungan sehingga menciptakan kondisi belajar bagi siswa; (4) memberikan bimbingan belajar kepada siswa; (5) kegiatan mempersiapkan siswa untuk menjadi warga negara yang baik; serta (6) suatu proses membantu siswa menghadapi kehidupan masyarakat seharihari (Hamalik, 2000).

\section{Persepsi atas Lingkungan Sekolah.} Syaiful Bahri Djamarah (2006) dan J. Drever (2010) menyatakan bahwa persepsi adalah suatu proses pengenalan atau identifikasi sesuatu dengan menggunakan panca indera (Djamarah, 2006; dan Drever, 2010). Sedangkan Jalaluddin Rakhmat (2005), sebagaimana dikutip oleh A.D.S. Krissandi \& Rusmawan (2015), mengemukakan bahwa persepsi adalah pengalaman tentang objek, peristiwa, atau hubungan-hubungan yang diperoleh dengan menyimpulkan informasi dan melampirkan pesan (Rakhmat, 2005; dan Krissandi \& Rusmawan, 2015:458).

Kesan yang diterima individu sangat tergantung pada seluruh pengalaman yang telah diperoleh melalui proses berfikir dan belajar, serta dipengaruhi pula oleh faktor yang berasal dari dalam diri individu. Dalam konteks ini, Mohd Aderi Che Noh \& Rohani Ahmad Tarmizi (2009) menyatakan bahwa persepsi sebagai aktivitas, yang memungkinkan manusia mengendalikan ransangan-ransangan yang sampai kepadanya melalui alat inderanya, memungkinkan individu mengenal lingkungannya (Noh \& Tarmizi, 2009).

Abul Hamid Rasyad (2003) juga menyatakan bahwa persepsi adalah suatau proses pengamatan seseorang yang berasal dari suatu kognisi secara terus-menerus dan dipengaruhi oleh informasi baru dari lingkungannya (Rasyad, 2003). Stephen P. Robbins (2006) menyatakan bahwa persepsi adalah sebagai proses, dimana individuindividu mengorganisasikan dan menafsirkan kesan indera mereka agar memberi makna kepada lingkungan (Robbins, 2006).

Mengenai lingkungan, Otto Soemarwoto (2001) menyatakan bahwa lingkungan 
adalah jumlah semua benda dan kondisi yang ada dalam ruang yang kita tempati dan turut mempengaruhi kehidupan manusia (Soemarwoto, 2001). Sejalan dengan pendapat Otto Soemarwoto (2001), Ngalim Purwanto (2006) juga menyatakan bahwa lingkungan adalah semua kondisi dalam dunia ini yang ada dalam cara-cara tertentu, yang mempengaruhi tingkah-laku manusia (Purwanto, 2006:28).

Sudharto P. Hadi (2001) menyatakan bahwa lingkungan mencakup sosial dan budaya, yang mempengaruhi kehidupan manusia (Hadi, 2001). Lingkungan perlu dikelola dengan baik untuk mendukung kelangsungan peri kehidupan dan kesejahteraan manusia (Soerjani, 2001). Dari ungkapan tersebut manusia diharapkan memperbaiki perilakunya dalam mengelola lingkungan, agar tercapai keserasian dengan lingungan yang baik.

Sarlito Wirawan Sarwono (1992 dan 1994) dan R.S. Kaplan \& D.P. Norton (2004) menyatakan bahwa kecenderungan manusia untuk selalu mengerti lingkungan adalah salah satu ciri utama manusia sebagai mahluk hidup yang berakal sehat. Sebagai mahluk yang berakal sehat, manusia senang mengetahui sesuatu, senang menerima informasi baru, dan senang membagi pengetahuannya kepada orang lain (Sarwono, 1992 dan 1994; dan Kaplan \& Norton, 2004).

Lingkungan sekolah, menurut Ahyari (2000), yaitu merupakan lingkungan dimana para guru melaksanakan pembelajaran (Ahyari, 2000). Dalam konteks lingkungan perusahaan, Sahdan (2000) menyatakan bahwa lingkungan merupakan keseluruhan sarana dan perasarana kerja yang ada di sekitar kita, yang dapat mempengaruhi pelaksanaan pekerjaan itu sendiri (Sahdan, 2000).

Selanjutnya, terdapat beberapa indikator lingkungan sekolah yang baik, yaitu: (1) penerangan yang cukup dan dapat meningkatkan motivasi guru dalam melaksanakan pembelajaran; (2) suhu udara yang tidak terlalu panas dan tidak terlalu dingin, sehingga membuat suasana yang baik dalam melaksanakan pembelajaran; (3) suara tidak bising yang dapat meningkatkan kosentrasi guru dalam melaksanakan pembelajaran; (4) pemilihan warna yang tepat sehingga membangkitkan gairah guru dalam melaksanakan pembelajaran; serta (5) keamanan yang dapat membuat guru merasa tenang dalam melaksanaknan pembelajaran (Sahdan, 2000; dan Chang, 2001).

Menurut Sedarmayanti (2001), lingkungan sekolah adalah keseluruhan alat dan bahan yang ada di sekitar kita serta pengaturan kerja, baik perseorangan maupun kelompok (Sedarmayanti, 2001). Selanjutnya dikatakan bahwa lingkungan sekolah terbagi menjadi dua, yaitu: (1) lingkungan sekolah secara fisik, dimana keadaan berbentuk fisik yang terdapat di sekitar tempat kerja, yang dapat mempengaruhi proses pembelajaran; dan (2) lingkungan sekolah non-fisik, dimana suatu keadaan yang berkaitan dengan hubungan pembelajaran, baik berhubungan dengan kepala sekolah, hubungan sesama guru, maupun hubungan dengan karyawan (Sedarmayanti, 2001). Jika kedua lingkungan tersebut baik, maka guru diharapkan mampu melaksanakan proses belajar-mengajar, sehingga kinerja guru sesuai dengan harapan.

\section{METODE}

Penelitian ini merupakan penelitian survey (Nazir, 1997; dan Arikunto, 2010). Variabel terikatnya adalah kinerja guru; sedangkan variabel bebasnya adalah motivasi mengajar dan persepsi atas lingkungan sekolah. Penelitian dilaksanakan di SMA (Sekolah Menengah Atas) Negeri 1 Tambun, Bekasi, Jawa Barat, Indonesia, pada tahun ajaran 2015/2016. Subjek penelitian adalah 120 orang siswa, yang diambil secara acak.

Pengumpulan data menggunakan skala Likert (Moleong, 1998; dan Dantes, 2012). Keabsahan data diperoleh dengan uji validitas dan reliabilitas. Berdasarkan hasil uji normalitas pada tingkat $\alpha 0.05$, maka subjek penelitian memiliki distribusi normal 
Tabel 1:

Uji Linieritas Regresi tentang Motivasi Mengajar terhadap Kinerja Guru

\begin{tabular}{|c|c|c|c|c|c|c|c|}
\hline \multicolumn{8}{|c|}{$A N O V A$} \\
\hline & & & $\begin{array}{l}\text { Sum of } \\
\text { Squares }\end{array}$ & $D f$ & $\begin{array}{l}\text { Mean } \\
\text { Square }\end{array}$ & $\boldsymbol{F}$ & Sig. \\
\hline \multirow{5}{*}{$\begin{array}{l}\text { Kinerja * } \\
\text { Motivasi }\end{array}$} & \multirow{3}{*}{$\begin{array}{l}\text { Between } \\
\text { Groups }\end{array}$} & (Combined) & 2817.934 & 32 & 186.535 & 3.747 & .000 \\
\hline & & Linearity & 2431.645 & 1 & 2431.645 & 74.683 & .000 \\
\hline & & Deviation from Linearity & 768.394 & 31 & 25.332 & .931 & .316 \\
\hline & \multicolumn{2}{|c|}{ Within Groups } & 4978.369 & 158 & 31.928 & & \\
\hline & \multicolumn{2}{|c|}{ Total } & 7253.174 & 193 & & & \\
\hline
\end{tabular}

Kriteria Pengujian: Nilai sig $0.316>0.05$ berarti persamaan regresi tentang motivasi mengajar terhadap kinerja guru adalah linier.

Tabel 2:

Uji Linieritas Regresi tentang Persepsi atas Lingkungan Sekolah terhadap Kinerja Guru

\begin{tabular}{|c|c|c|c|c|c|c|c|}
\hline \multicolumn{8}{|c|}{$A N O V A$} \\
\hline & & & $\begin{array}{l}\text { Sum of } \\
\text { Squares }\end{array}$ & $D f$ & $\begin{array}{l}\text { Mean } \\
\text { Square }\end{array}$ & $\boldsymbol{F}$ & Sig. \\
\hline \multirow{5}{*}{$\begin{array}{l}\text { Kinerja * } \\
\text { Lingkungan }\end{array}$} & \multirow{3}{*}{$\begin{array}{l}\text { Between } \\
\text { Groups }\end{array}$} & (Combined) & 3646.118 & 30 & 274.825 & 3.972 & .000 \\
\hline & & Linearity & 3852.944 & 1 & 3852.944 & 47.158 & .000 \\
\hline & & Deviation from Linearity & 2793.421 & 29 & 34.965 & .747 & .357 \\
\hline & \multicolumn{2}{|c|}{ Within Groups } & 7495.183 & 147 & 38.389 & & \\
\hline & \multicolumn{2}{|c|}{ Total } & 6591.428 & 162 & & & \\
\hline
\end{tabular}

Kriteria Pengujian: Nilai sig $=0.357>0.05$ berarti persamaan regresi persepsi atas lingkungan sekolah terhadap kinerja guru linier.

(Sirkin, 2006; dan Riduan, 2010). Mengenai konstalasi penelitian, uji linieritas regresi tentang motivasi mengajar, dan uji linieritas regresi tentang persepsi atas lingkungan sekolah dapat dilihat dalam bagan 1 , tabel 1, dan tabel 2 .

\section{HASIL DAN PEMBAHASAN}

Hasil. Motivasi mengajar berpengaruh secara signifikan terhadap kinerja guru. Dari kriteria pengujian: Nilai $t_{\text {hitung }}=$ $3.574>$ nilai $\mathrm{t}_{\text {tabel }}=2.037$ dan nilai sig. $=0.000<0.05$, maka hasilnya dapat dilihat dalam tabel 3.

Persepsi atas lingkungan sekolah berpengaruh secara signifikan terhadap kinerja guru, dengan kriteria pengujian: Nilai $\mathrm{t}_{\text {hitung }}=3.885>\mathrm{t}_{\text {tabel }}=2.037$ dan

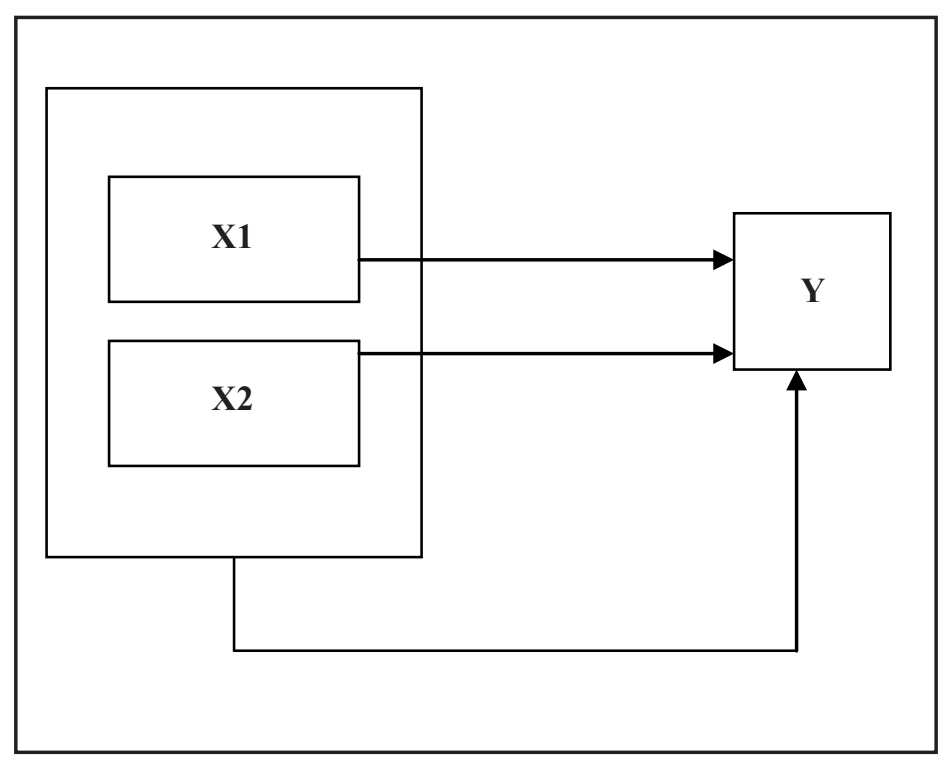

Keterangan :

$\mathrm{Y}=$ Kinerja guru.

$\mathrm{X} 1=$ Motivasi mengajar.

$\mathrm{X} 2=$ Persepsi atas lingkungan sekolah.

Bagan 1:

Konstalasi Penelitian 
Tabel 3:

Uji T Coefficients ${ }^{a}$

\begin{tabular}{|c|c|c|c|c|c|c|}
\hline & \multirow{2}{*}{ Model } & \multicolumn{2}{|c|}{ Unstandardized Coefficients } & \multirow{2}{*}{$\frac{\text { Standardized Coefficients }}{\text { Beta }}$} & \multirow{2}{*}{$T$} & \multirow{2}{*}{ Sig. } \\
\hline & & B & Std. Error & & & \\
\hline \multirow[t]{3}{*}{1} & (Constant) & 18.914 & 3.536 & & 3.971 & .000 \\
\hline & Motivasi Mengajar & .479 & .064 & .419 & 3.574 & .000 \\
\hline & Lingkungan & .351 & .072 & .383 & 3.885 & .001 \\
\hline
\end{tabular}

Keterangan: a. Dependent Variable adalah Kinerja.

Tabel 4:

Uji F

ANOVA

\begin{tabular}{llccccc}
\hline & Model & Sum of Squares & Df & Mean Square & F & Sig. \\
\hline 1 & Regression & 4217.359 & 2 & 2817.538 & 63.827 & $.000^{\mathrm{a}}$ \\
& Residual & 5631.852 & 125 & 32.506 & & \\
\cline { 2 - 6 } & Total & $\mathbf{6 4 3 8 . 1 7 2}$ & $\mathbf{1 9 4}$ & & & \\
\hline
\end{tabular}

a. Predictors: (Constant) Motivasi dan Lingkungan.

b. Dependent Variable: Kinerja.

Tabel 5:

Koefisien Reterminasi

Model Summary

\begin{tabular}{ccccc}
\hline Model & $\boldsymbol{R}$ & $\boldsymbol{R}$ Square & Adjusted $\boldsymbol{R}$ Square & Std. Error of the Estimate \\
\hline 1 & $.872^{\mathrm{a}}$ & .627 & .417 & 3.85136 \\
\hline
\end{tabular}

a. Predictors: (Constant) Motivas dan Lingkungan.

nilai sig. $=0.001<0.05$. Lihat tabel 4 .

Motivasi mengajar dan persepsi atas lingkungan sekolah, secara bersama-sama, berpengaruh signifikan terhadap kinerja guru, dengan kriteria pengujian: Nilai $\mathrm{F}_{\text {hitung }}=$ $63.827>\mathrm{F}_{\text {tabel }}=2.315$ dan nilai Sig $=0.000$ $<0.05$. Lihat tabel 5 .

Nilai koefisien determinasi $\left(\mathrm{R}^{2}\right)$ sebesar 0.627 , artinya bahwa $62.7 \%$ motivasi mengajar dan persepsi atas lingkungan sekolah mempunyai hubungan yang kuat terhadap kinerja guru; sedangkan sisanya, yakni $37.3 \%$ (100\% - 63.7\%) tidak dianalisis dalam penelitian ini.

Pembahasan. Motivasi mengajar berpengarauh secara signifikan terhadap kinerja guru. Hasil penelitian menunjukan bahwa motivasi mengajar berpengaruh secara signifikan terhadap kinerja guru. Hal ini sesuai dengan pendapat Suradinata
(1996), yang mengemukakan bahwa motivasi merupakan tenaga pendorong atau penggerak yang menyebabkan guru bertingkah-laku untuk mencapai tujuan pembelajaran (Suradinata, 1996).

Kemudian Utari Sumarno et al. (1994) juga menyatakan bahwa dalam proses belajar-mengajar di kelas, guru membantu siswa dan memberikan bimbingan secara individu bagi siswa, yang mengalami kesulitan mengerjakan tugasnya (Sumarno et al., 1994). Manakala O. Sutisna (2000) mengatakan bahwa kinerja merupakan suatu perilaku yang menunjukan kompetensi relevan dengan tugas yang realistis untuk memenuhi kebutuhan pembelajaran (Sutisna, 2000).

Menurut Hasan Alwi et al. eds. (1995), dalam KBBI: Kamus Besar Bahasa Indonesia, kinerja itu meliputi: (1) tugas sesuai waktunya; (2) prestasi yang 
diperlihatkan; dan (3) tugas sesuai rencana (Alwi et al. eds., 1995). L.J. Moleong (1998) juga menyatakan bahwa kinerja adalah suatu hasil yang diinginkan oleh suatu organisasi (Moleong, 1998). Sementara itu, Syaiful Bahri Djamarah (2006) menyatakan bahwa pengetahuan dan kemampuan yanag dimilki oleh guru akan menentukan kinerja. Hal tersebut memiliki makna bahwa pengetahuan dan kemampuan yang dimiliki guru akan memperoleh prestasi yang baik dalam melaksanakan pembelajaran (Djamarah, 2006).

Hasil penelitian juga menunjukan bahwa persespsi atas lingkungan sekolah berpengaruh signifikan terhadap kinerja guru. Hal ini sesuai dengan pendapat Jalaluddin Rakhmat (2005), sebagaimana dikutip juga oleh A.D.S. Krissandi \& Rusmawan (2015), bahwa persepsi adalah pengalaman tentang objek, peristiwa, atau hubungan-hubungan yang diperoleh dengan menyimpulkan informasi dan melampirkan pesan (Rakhmat, 2005; dan Krissandi \& Rusmawan, 2015:458). Kesan yang diterima individu sangat tergantung pada seluruh pengalaman yang telah diperoleh melalui proses berfikir dan belajar, serta dipengaruhi oleh faktor yang berasal dari dalam diri individu.

Dalam konteks ini, Mohd Aderi Che Noh \& Rohani Ahmad Tarmizi (2009) menyatakan bahwa persepsi, sebagai aktivitas yang memungkinkan manusia mengendalikan rangsangan-rangsangan yang sampai kepadanya melalui alat indera, memungkinkan individu mengenal lingkungannya (Noh \& Tarmizi, 2009). Hal ini juga sesuai pendapat Otto Soemarwoto (2001), yang menyatakan bahwa lingkungan merupakan suatu ruang yang ditempati untuk mendukung kegiatan pembelajaran (Soemarwoto, 2001).

Sahdan (2000) menyatakan bahwa lingkungan merupakan keseluruhan sarana dan perasarana kerja yang ada di sekitar kita, yang dapat mempengaruhi proses pembelajaran. Selanjutnya dikatakan bahwa terdapat beberapa indikator lingkungan sekolah yang baik, yaitu: penerangan yang cukup, suhu udara yang tidak terlalu panas dan tidak terlalu dingin, suara yang tidak bising, serta warna yang sesuai (Sahdan, 2000). Sadar Malayu S.P. Hasibuan (2001) juga menyatakan bahwa kinerja dapat dicapai oleh guru apabila tugas-tugas yang diberikan sesuai kemampuannya dan didudukung oleh lingkungan kerja yang baik (Hasibuan, 2001).

Hasil penelitian menunjukan bahwa motivasi mengajar dan persepsi atas lingkungan sekolah, secara bersamasama, memiliki pengaruh yang signifikan terhadap kinerja guru. Mengacu pendapat J.L. McGaugh (1977) menyatakan bahwa motivasi yang dimiliki guru merupakan dasar kekuatan atau daya yang menggerakan untuk melaksanakan pembelajaran (McGaugh, 1977). Hal ini juga sesuai dengan pendapat Utari Sumarno et al. (1994), yang menyatakan bahwa dalam proses belajarmengajar di kelas, guru membantu siswa dalam memberikan bimbingan secara individu bagi siswa yang mengalami kesulitan mengerjakan tugasnya (Sumarno et al., 1994).

Stephen P. Robbins (2006) menyatakan persepsi sebagai proses dimana individuindividu mengorganisasikan dan menafsirkan kesan indera mereka agar memberi makna kepada lingkungan (Robbins, 2006). Manakala Abul Hamid Rasyad (2003) menyatakan bahwa persepsi adalah suatu proses pengamatan seseorang yang berasal dari suatu kognisi secara terus-menerus dan dipengaruhi oleh informasi baru dari lingkungan (Rasyad, 2003).

Akhirnya, sesuai dengan pendapat Mohamad Soerjani (2001) yang menyatakan bahwa lingkungan sekolah perlu dikelola sebaik-baiknya untuk mendukung kelangsungan proses belajar-mengajar (Soerjani, 2001); maka pendapat M.N. Nasution (2001) juga menyatakan bahwa keberhasilan belajar siswa turut ditentukan oleh peran guru selama interaksi proses belajarmengajar berlangsung (Nasution, 2001). 


\section{KESIMPULAN}

Hasil pengolahan data diperoleh nilai $\mathrm{t}_{\text {hitung }}=3.574>\mathrm{t}_{\text {tabel }}$ pada $\alpha 5 \%=2.037$, yang artinya bahwa motivasi mengajar berpengaruh secara signifikan terhadap kinerja guru. Hasil pengolahan data diperoleh nilai $\mathrm{t}_{\text {hitung }}=3.885>$ nilai $\mathrm{t}_{\text {tabel }}$ pada $\alpha 5 \%=2.037$, yang artinya bahwa persepsi atas lingkungan sekolah berpengaruh secara signifikan terhadap kinerja guru. Hasil pengolahan data diperoleh nilai koefisien determinasi $\left(\mathrm{R}^{2}\right)$ sebesar 0.627 atau $62.7 \%$, yang artinya bahwa motivasi mengajar dan persepsi atas lingkungan sekolah, secara bersama-sama, berpengaruh secara signifikan terhadap kinerja guru. Dan sisanya, sebanyak $37.3 \%(100 \%$ - 62.7\%) dipengaruhi oleh faktor lain, yang tidak dianalisi dalam penelitian ini.

Guru perlu diperhatikan kesejahteraannya supaya mempunyai motivasi dalam melaksanakan pembelajaran. Lingkungan sekolah perlu diperbaiki supaya siswa dapat mengikuti pembelajaran dengan baik. Guru yang mempunyai kinerja baik perlu diberikan penghargaan, baik berupa insentif maupun promosi jabatan. Sarana dan prasarana sekolah perlu diperhatikan, supaya proses belajarmengajar dapat terlaksana dengan baik. ${ }^{1}$

\section{Referensi}

Ahyari. (2000). Aplikasi Psikologi dalam Manajemen Sumber Daya Manusia. Jakarta: Pusgrafindo.

Alwi, Hasan et al. [eds]. (1995). KBBI: Kamus Besar Bahasa Indonesia. Jakarta: Departemen Pendidikan dan Kebudayaan Republik Indonesia dan Balai Pustaka.

Arikunto, Suharsimi. (2010). Prosedur Penelitian: Suatu Pendekatan Praktik. Jakarta: PT Rineka Cipta. Atkinson, R.L. \& E.R. Hilgard. (1982). Introduction

\footnotetext{
${ }^{1}$ Pernyataan: Artikel ini adalah karya asli saya sendiri, ianya bukan hasil dari plagiat dan tidak pernah dikirimkan atau diterbitkan oleh jurnal ilmiah yang lain. Saya bersedia mendapatkan sanksi akademik yang setimpal, sekiranya pernyataan yang saya buat ini, ternyata di kemudian hari, adalah tidak benar.
}

to Psychology. London: Harcourt Brance Jovanovich, Inc.

Bloom, B.S. (1981). Taxonomy of Educational Objectives. New York: Longman.

Chang, William. (2001). Moral Lingkungan Hidup. Yogyakarta: Penerbit Kanisius, Terjemahan.

Dantes, Nyoman. (2012). Metodologi Penelitian. Yogyakarta: Penerbit Andi.

Depdiknas RI [Departemen Pendidikan Nasional Republik Indonesia]. (2003). Undang-Undang Republik Indonesia Nomor 20 Tahun 2003 tentang Sistem Pendidikan Nasional. Jakarta: Biro Hukum dan Organisasi, Sekretariat Jenderal Departemen Pendidikan Nasional.

Desler, G. (2000). Manajemen Sumber Daya Manusia. Jakarta: Penerbit Index, Terjemahan.

Dimyati, M. \& Moedjianto. (1992). Strategi BelajarMengajar. Jakarta: Rineka Cipta.

Djamarah, Syaiful Bahri. (2006). Strategi BelajarMengajar. Jakarta: PT Rineka Cipta, edisi revisi.

Drever, J. (2010). Kamus Psikologi. Jakarta: Bina Aksara, Terjemahan.

Gagne, R.M. (1977). The Condition of Learning. New York: Holt, Rinehart \& Winston.

Hadi, Sudharto P. (2001). Aspek Sosial AMDAL. Yogyakarta: Gadjah Mada University Press.

Hamalik, Oemar. (2000). Manajemen Peningkatan Mutu Berbasis Sekolah. Yogyakarta: FIP UNY [Fakultas Ilmu Pendidikan, Universitas Negeri Yogyakarta].

Hasibuan, Sadar Malayu S.P. (2001). Manajemen Sumber Daya Manusia. Jakarta: Bumi Aksara.

Joewono, Hadi. (1985). "Jangan Sekedar Servis" dalam majalah Intisari. Jakarta: Oktober.

Kaplan, R.S. \& D.P. Norton. (2004). "Measuring the Strategic Readiness of Intangible Assets" in Harvard Business Review, 82(2), pp.52-63.

Klausmeir, Harkert J. (1991). Educational Psychology. New York: Harpes and Ross.

Krathwol, C.N. \& N. Anderson. (2001). A Taxonomy for Learning, Teaching, and Assessing: A Revision of Bloom's Taxonomy of Educational Objectives. New York: Addison Wesley Longman.

Krissandi, A.D.S. \& Rusmawan. (2015). "Kendala Guru Sekolah Dasar dalam Implementasi Kurikulum 2013" dalam Cakrawala Pendidikan, Th.XXXIV, No.3 [Oktober]. Tersedia secara online juga di: http://download.portalgaruda.org/article. php?article $=390136 \&$ val $=445 \&$ title $[$ diakses di Jakarta, Indonesia: 15 Januari 2017].

Maslow, Abraham H. (2006). On Dominace, Self Esteen, and Self Actualization. Ann Kaplan: Maurice Basset.

McGaugh, J.L. (1977). Psychology: An Experimental Approach. San Francisco and California: Albion Publishing Company. 
Melinda, H. \& D.J. Russel. (1997). Instructional Design. London: Clipper.

Moleong, L.J. (1998). Metodologi Penelitian Kualitatif. Bandung: Remaja Rosda Karya.

Nasution, M.N. (2001). Manajemen Mutu Terpadu: Total Quality Management. Jakarta: Ghalia Indonesia.

Nazir, Moh. (1997). Metodologi Penelitian. Jakarta: Ghalia Indonesia.

Noh, Mohd Aderi Che \& Rohani Ahmad Tarmizi. (2009). "Persepsi Pelajar terhadap Amalan Pengajaran Tilawah Al-Quran (Students' Perception toward Teaching Tilawah Al-Quran)" dalam Jurnal Pendidikan Malaysia, 34(1), ms.93-109. Tersedia secara online juga di: http://www.ukm.my/jurfpend/ journal/vol\%2034\%202009/pdf/BAB[06].pdf [diakses di Jakarta, Indonesia: 15 Januari 2017].

Nurdin. (2014). "Pengaruh Metode Penyuluhan dan Tingkat Pendidikan terhadap Tengetahuan Berwawasan Lingkungan" dalam JIP: Jurnal Ilmu Pendidikan, Jilid 20, Nomor 2 [Desember], hlm.201-206.

Piaget, J.K. (1985). The Instructional Design Process. New York: Harper and Row Publishers.

Purwanto, Ngalim. (2006). Psikologi Pendidikan. Bandung: PT Remadja Rosdakarya.

Rakhmat, Jalaluddin. (2005). Psikologi Komunikasi. Bandung: PT Remaja Rosdakarya.

Rasyad, Abul Hamid. (2003). Menjadi Milyarder Muslim. Jakarta: Penerbit Pustaka Al-Kautsar.

Reigeluth, J. \& S. Merril. (1963). Instructional Design and Method. New Jersey: Longman.

Riduan. (2010). Skala Pengukuran Variabel-variabel Penelitian. Bandung: Penerbit Alfabeta.

Robbins, Stephen P. (2006). Perilaku Organisasi. Jakarta: PT Indeks Kelompok Gramedia, Terjemahan, edisi kesepuluh.

Rusman. (2009). Manajemen Kurikulum. Jakarta: Raja Grafindo.

Russel, D.J. \& R. Heinrich. (1989). Instructional Media and the Technologies of Instruction. New York: MacMillan Publishing Company.

Sahdan. (2000). Manajemen Perusahaan. Jakarta: Raja Grafindo.

Sallis, E. \& G. Jones. (2002). Knowledge Management in Education. London: Biddies Ltd.
Sarwono, Sarlito Wirawan. (1992). Psikologi Lingkungan. Jakarta: UI [Universitas Indonesia] Press.

Sarwono, Sarlito Wirawan. (1994). Psikologi Sosial. Jakarta: Balai Pustaka.

Schuler, R.S. \& V.L. Huber. (1993). Personnel and Human Resources Management. Minneapolis/St. Paul: West Publishing Company.

Sedarmayanti. (2001). Sumber Daya Manusia dan Produktivitas Kerja. Bandung: Penerbit Monder.

Segall, M.H. (1999). Human Behavior in Global Perspective: An Introduction to Cross Cultural Psychology. USA [United States of America]: Allyn and Bacon.

Sirkin, R.M. (2006). Statistic for the Social Sciences. California: Sage Publications, Inc.

Slameto. (1991). Belajar dan Faktor-faktor yang Mempengaruhinya. Jakarta: Rineka Cipta.

Soemarwoto, Otto. (2001). Atur Diri Sendiri. Yogyakarta: Gadjah Mada University Press.

Soerjani, Mohamad. (2001). Institut Pendidikan dan Pengembangan Lingkungan. Jakarta: Forum Lingkungan Dewan Riset Nasional.

Sudjana, H.D. (2001). Metode dan Teknik Pembelajaran Partisipatif. Bandung: Falah Indonesia.

Sumarno, Utari et al. (1994). "Suatu Alternatif Pengajaran untuk Meningkatkan Kemampuan Pemecahan Masalah Matematika pada Guru dan Siswa SMP”. Laporan Penelitian Tidak Diterbitkan. Bandung: IKIP [Institut Keguruan dan Ilmu Pendidikan] Bandung.

Suradinata. (1996). Kepemimpinan. Bandung: Remaja Rosdakarya.

Sutisna, O. (2000). Administrasi Pendidikan: Dasar Teoretis untuk Praktek Profesional. Bandung: Penerbit Angkasa.

Tilaar, H.A.R. (2001). Manajemen Pendidikan Nasional. Bandung: Remaja Rosdakarya.

Umaedi. (1998). Manajemen Peningkatan Mutu Berbasis Sekolah. Yogyakarta: FIP UNY [Fakultas Ilmu Pendidikan, Universitas Negeri Yogyakarta].

Whitmore, J. (1997). Coaching for Performance. Jakarata: Gramedia Pustaka Utama, alih bahasa oleh Y. Dewi Helly Purnomo. 